\title{
Con María en camino hacia el Padre*
}

\author{
Oswaldo Martínez Mendoza, Ph.D*
}

Recibido: 30 de mayo de 2014 • Aprobado: 3 de agosto de 2014

\section{Resumen}

El Padre es la primera persona divina de la Santísima Trinidad, origen y meta de toda la historia de la salvación; es la Persona que ha encontrado en María "la morada en donde su Hijo y su Espíritu pueden habitar entre los hombres" (CEC, 719); por este motivo la Virgen de Nazaret se halla implicada en el punto culminante y definitivo de la autorrevelación a la humanidad. En el presente estudio, en primer lugar, se aborda el tema de la elección de María por parte del Padre, se establecen los fundamentos escriturísticos y teológicos, y en segundo lugar se trata la respuesta de la Virgen a la elección y al amor del Padre; y finalmente se incluye una reflexión sobre el culto mariano en cuanto camino hacia el Padre.

Palabras clave: Dios-Padre, María, gratuidad, humanidad, filiación.

* Este artículo es resultado de la investigación y estudio del autor.

** Doctor en Teología de la Pontificia Universidad Gregoriana de Roma, licenciado en Teología con Especialización en Cristología por la Universidad Gregoriana de Roma, Estudios de Mariología en el Marianum de Roma, Estudios de Espiritualidad Misionera de la Pontificia Universidad Urbaniana de Roma, Estudios de Patrística en el Agustinianum de Roma. Es sacerdote de la arquidiócesis de Tunja y Vicerrector de la Fundación Universitaria Juan de Castellanos de Tunja. Correo electrónico: oswmart@gmail.com 


\title{
With Mary on the road to the Father
}

\begin{abstract}
The Father is the first divine person of the Holy Trinity, origin and goal of all salvation history; is the Person who has found in Mary "the dwelling place where his Son and his Spirit could dwell among men" (CCC, 719); for this reason the Virgin of Nazareth is involved in the culminating and definitive point of self-revelation to humanity. In this study, firstly, is approached the issue of the election of Mary by the Father, the scriptural and theological foundations are laid, and secondly is addressed the response of the virgin to the election and love of the Father; and finally is included a reflection on Marian devotion as road to the Father.
\end{abstract}

Keywords: God-Father, Mary, gratitude, humanity, relationship.

\section{Avec Marie sur le chemin vers le Père}

\section{Résumé}

Le Père est la première personne de la divine Trinité, origine et but de toute histoire du salut; c'est la personne qui a trouvé Marie "la demeure où son Fils et son Esprit peuvent habiter parmi les hommes" (CEC, 719); pour ce motif la Vierge de Nazareth se trouve impliquée au point culminant et définitif de l'autorevelation à l'humanité. Dans l'étude présente, en premier lieu, on aborde le sujet de l'élection de Marie de la part du tout puissant, nous établissons les fondements des écritures sainte et théologiques. En deuxième lieu nous traitons de la réponse de la Vierge à l'élection et à l'amour du Père; et finalement nous incluons une réflexion sur le culte marial, chemin menant au Seigneur.

Mots-clés: Dieu-le père, Marie, gratitud, humanité, filiation. 


\section{Introducción}

El Padre, fuente y origen de toda la divinidad, es, de modo particular, un Dios rico en misericordia, a quien Jesucristo nos ha revelado. Cristo hace presente al Padre, mediante sus hechos y palabras; él es el signo del Padre y, por tanto, los hombres de todos los tiempos, cuando se acercan a Cristo, pueden ver al Padre; además, junto con la revelación del Padre y de su amor, se da la revelación del ser humano y de su vocación. Cristo es esencialmente y desde la eternidad el hijo de Dios; cuando se dirige al Padre está indicando su identidad como Hijo: "Yo y el Padre somos uno" (Jn 10, 30). Su misión de mesías consiste en hacer presente al Padre en cuanto amor y misericordia; aún más, él mismo es en cierto sentido la misericordia. Con sus gestos concretos reveló el misterio profundo del Padre, su solicitud y su amor hacia cada uno de los hombres. Por otra parte, no se puede comprender a Jesucristo sino como el hijo enviado por el Padre "en la plenitud de los tiempos" (Ga 4, 4). La perspectiva última de la Iglesia es la misma de Cristo, una peregrinación hacia la casa del Padre, en la que él nos precede, porque se ha ido a la casa del Padre a prepararnos un lugar (Jn 14, 2-3). Esta peregrinación afecta a lo íntimo de la persona y se prolonga después a la comunidad creyente, para alcanzar a la humanidad entera. Por Cristo, la Palabra hecha carne, y con el Espíritu, podemos llegar hasta el Padre y participar de la naturaleza divina. La revelación tiene así una doble dimensión: en primer lugar, una dimensión divina, mediante la cual el ser humano, en Cristo, encuentra el amor y la fidelidad del Creador y Padre, que lo ha elegido en su Hijo, para la gracia y la gloria, y, en segundo lugar, una dimensión humana en cuanto la elección divina constituye la grandeza inaudita del ser humano. Estas dos dimensiones de la revelación se encuentran en Cristo, en la medida en que, en él, el Padre se nos acerca a y, a su vez, podemos orientarnos al Padre en Cristo Jesús.

La misericordia es la característica esencial del Padre, que se manifestó plenamente mediante la redención realizada por Cristo como expresión de su amor y de su solicitud por nosotros. Jesucristo es el rostro humano de la misericordia del Padre; quien se encuentre con Cristo se encuentra con la misericordia; la revelación de la misericordia del Padre en Jesucristo culmina con el misterio pascual: de este modo, la redención comporta la revelación de la misericordia en su plenitud. La comunicación del amor de Dios pertenece a su vida íntima, es decir a la comunión trinitaria, en la que el Espíritu Santo es la hipóstasis personal del amor que viene del Padre y se comunica a la criatura humana mediante el sacrificio redentor de Cristo. 
El Padre es la Primera Persona Divina de la Santísima Trinidad, origen y meta de toda la historia de la salvación; es la Persona que ha encontrado en María "la Morada en donde su Hijo y su Espíritu pueden habitar entre los hombres"1; por este motivo la Virgen de Nazaret se halla implicada en el punto culminante y definitivo de la autorrevelación a la humanidad.

La relación particular del Padre con María² es un tema que estuvo "casi ausente en el Concilio" (De Fiores, 1990, p. 126), pero que ahora se está recuperando en la reflexión teológica ${ }^{3}$. En el presente estudio, en primer lugar se abordará el tema de la elección de María por parte del Padre, se establecerán los fundamentos escriturísticos y teológicos, y, en segundo lugar, se tratará la respuesta de la Virgen a la elección y al amor del Padre. Finalmente, se incluye una reflexión sobre el culto mariano como un camino hacia el Padre.

\section{El Padre ama y elige a María}

Tomamos como punto de partida la elección realizada por el Padre, pues, en el misterio de Cristo, María está presente ya "antes de la creación del mundo" como aquella que el Padre "ha elegido" como madre de su hijo en la encarnación, y, junto con el Padre, la ha elegido el Hijo, confiándola eternamente al Espíritu de santidad $^{4}$. La elección de María por parte del Padre tiene un marco trinitario, en cuanto es elegida para ser la madre del Hijo y confiada al Espíritu Santo; ella es la hija predilecta del Padre. Así pues, podemos poner como fundamento de la

\section{CEC 721.}

2 Cf. Amato (2000). La bibliografía actual sobre la relación del Padre con María es escasa; se encuentran alusiones en algunas obras, pero sin ser el tema principal; a modo de ejemplo la obra de mariología de D. Bertetto (1988, pp. 195-199) y de M. Navarro (1987, pp. 731-740), encuentran tres temas que podrían dar una visión de la relación Padre-María: 1) el de la creación, "que pone de relieve la similitud que existe entre la palabra creadora de Dios en el Génesis - '¡Hágase!' - y la de María en el texto de Lucas — 'que se haga en mí” —”; 2) el "de la participación que tiene María en la paternidad divina, por ser la Madre del Hijo de Dios"; 3) el "de la función de filtro que parece tener María en los evangelios, en cuanto que en ella se realiza el paso desde Yahvé, el Dios de Israel, al 'Abba', el Padre de Jesús" (Navarro, 1987, p. 734, 853862). Confrontar también L. Sartori (1999, pp. 237-263).

3 A. Amato (2000, pp. 608-610; 1998, pp. 117-133).

4 Pablo VI, en la exhortación apostólica Marialis Cultus, se había referido a la elección de María por parte del Padre: “con vistas a Él [Cristo], Dios Padre la eligió desde toda la eternidad como Madre toda santa y la adornó con dones del Espíritu Santo que no fueron concedidos a ningún otro" (Pablo VI, 1976, p. 25). 
reflexión sobre el tema de la elección de María tres significativos textos de la revelación neotestamentaria: en primer lugar, el texto de Efesios; en segundo lugar, el texto de Gálatas, y, en tercer lugar, el texto de Lucas sobre la anunciación.

1. La carta a los Efesios comienza con un grandioso himno de alabanza a Dios Padre por el eterno designio de la salvación: “Bendito sea Dios y Padre de nuestro Señor Jesucristo, que nos ha bendecido con toda clase de bendiciones espirituales, en los cielos, en Cristo" (Ef 1, 3). Estas palabras revelan el designio de Dios Padre: su plan de salvación en Cristo, que está dirigido a todos los seres humanos. Precisamente, con la creación a imagen y semejanza de Dios (Gn 1, 26), el hombre fue incluido en el proyecto divino que tiene su cumplimiento en la plenitud de los tiempos con la venida de Cristo (Aldama, 1995, p. 166). La humanidad fue elegida por el Padre, rico en misericordia, para participar en su plan de salvación en Cristo. Este plan es, por tanto, universal y comprende a toda la humanidad; tiene como objetivo la filiación adoptiva; es eterno, porque coincide con el beneplácito del Padre y ha sido revelado plenamente con la venida de Cristo. La Virgen Madre tiene un lugar especial en este plan divino de la salvación, pues el Padre, rico en misericordia, la elige como hija de Sión ${ }^{5}$ y la colma de su gracia con vistas a la filiación adoptiva de sus hermanos. Ella se ubica, entonces, en un punto crucial del escenario del drama salvífico que comenzó en el Antiguo Testamento y que llegó a su plenitud en el Nuevo Testamento con Cristo; en ella se manifiesta la extrema gratuidad del amor de Dios, que la eligió en previsión de la encarnación de su Hijo. En ella se refleja, por tanto, de manera única, el tema de la elección, que es esencial para comprender el proyecto de Dios sobre la humanidad; ella asume en sí la historia del pueblo elegido, siendo insinuada proféticamente en la promesa dada a nuestros primeros padres caídos en el pecado, según el libro del Génesis $(3,15)$; ella es la virgen que concebirá y dará a luz un hijo cuyo nombre será Emmanuel, según las palabras de Isaías $(7,14)^{6}$. Así como Israel fue elegido para la salvación de la humanidad, María es elegida en función del Salvador de la humanidad.

5 Confrontar De la Potterie (1988, pp. 102-118); X. Pikaza (1994, pp. 9-43), y E.G. Mori (1988, pp. 824-834).

6 LG 55. Sobre Génesis (3, 15), confrontar R. Laurentin (1954, pp. 77-156). 
2. Gálatas $(4,4)$ es el primer testimonio mariano del Nuevo Testamento. La palabra clave es hijo, aplicada tanto a Cristo como a los cristianos, bien que en diversa dimensión. Pero el misterio de Dios, que se ha hecho presente de manera singular en Jesucristo, el Hijo, incluye también al Padre y al Espíritu. Afirma A. Amato que "este famoso texto de Pablo ofrece dentro de su concisión la base bíblica más antigua de las relaciones Dios Padre-María" (2001, p. 606). En efecto, en el texto bíblico se advierte:

al llegar la plenitud de los tiempos, envió Dios a su Hijo, nacido de mujer, nacido bajo la ley, para rescatar a los que se hallaban bajo la ley, para que recibieran la filiación adoptiva. La prueba de que sois hijos es que Dios ha enviado a vuestros corazones el Espíritu de su Hijo que clama: ¡Abbá, Padre! (Ga 4, 4-6)

Gálatas $(4,4)$ constituye el punto de partida de la reflexión sobre la dimensión trinitaria de la función de María en la historia de la salvación y, especialmente, de su relación con el Padre. Ella es elegida en previsión de la encarnación del Hijo de Dios a quien el Padre ha confiado la obra de la salvación. Por eso, además de ser madre, es la primera entre los redimidos, "la primera hija adoptiva del Padre en el Hijo"7; en ella el Padre ha encontrado la colaboración total y fiel a su plan de salvación.

La plenitud de los tiempos significa precisamente la intensidad del actuar divino de la Santísima Trinidad en el momento de la encarnación: esta plenitud delimita el momento, fijado desde toda la eternidad, en el cual el Padre envió a su Hijo. Este acontecimiento salvífico se convierte así en el punto clave en la historia del hombre en la tierra, entendida como historia de salvación. En este advenimiento se revela tanto la dimensión divina como la humana de la historia de la salvación, en cuanto es Dios Padre quien en la plenitud de los tiempos decreta, por amor, el envío de su Hijo, y, por otra parte, mediante este acontecimiento, Dios sale al encuentro de las aspiraciones del espíritu humano que busca a Dios. En consecuencia, la Virgen María se encuentra en el centro del cumplimiento de las promesas de Dios. Ella es testigo privilegiado del actuar del Padre en favor nuestro, porque conoció la intensidad de su amor en el envío de su Hijo; la Madre del Redentor nos ayuda a descubrir en el origen de toda la obra de la salvación la

7 Confrontar A. Amato (2000, p. 32); RM 8, y LG 53: “Redimida de modo eminente, en previsión de los méritos de su Hijo". 
acción del Padre, que invita al hombre a hacerse hijo en su Hijo; en efecto, todo viene de la voluntad del Padre, que envió a su Hijo al mundo. Este designio del Padre se realizó en la encarnación, obra del Espíritu Santo y de la colaboración de la 'mujer', que, así, entró a formar parte de la economía de la comunicación de la Trinidad con la humanidad. María apareció antes de Cristo en el horizonte de la historia de la salvación; es decir que en función de este acontecimiento salvífico, Dios Padre la eligió desde toda la eternidad para ser madre de su Hijo. Ella es la hija de Sión en la que se cumplen las promesas del Dios de la alianza. En este orden de la alianza de Dios con los hombres en la plenitud de los tiempos ha sido introducida la maternidad de la mujer. Ella es un don particular del Padre a su Hijo para la salvación de la humanidad, pues ha elegido para su Hijo una madre virgen, para dar más ampliamente a la humanidad su amor de Padre, como también, Cristo es para María el don más precioso del Padre.

3. El texto de Lucas de la anunciación (1,26-38) es el tercer texto bíblico en el cual podemos fundamentar la relación del Padre con la Theotokos ${ }^{8}$. Ella es introducida en el misterio de Cristo mediante el ángel enviado por el Padre. Este acontecimiento se enmarca dentro de la promesa de Israel, el primer pueblo destinatario de las promesas de Dios. Se puede relacionar el saludo del ángel a María ("Alégrate, llena de gracia, el Señor está contigo") con el pasaje de Efesios: "Bendito sea el Dios y Padre de nuestro Señor Jesucristo, que nos ha bendecido con toda clase de bendiciones espirituales, en los cielos, en Cristo" $(1,3)$, así como con las palabras de Isabel: "bendita tú entre las mujeres" (Lc 1, 42). Esta bendición brota del amor que, en el Espíritu Santo, une al Padre el Hijo consustancial. La gracia aparece aquí como la participación en la vida trinitaria mediante la encarnación de Cristo, como un don especial que proviene de la vida trinitaria de Dios que es amor (1 Jn 4, 8); fruto de ese amor es la elección de la que habla la carta a los Efesios. Esta bendición se refiere a María de modo especial y excepcional, porque efectivamente en ella derramó el Padre toda la plenitud de su gracia y de su amor.

En María la gracia se identifica con la elección del Padre; ella es, por tanto, la eterna amada del Padre. El saludo del ángel se refiere ante todo a la elección de la

8 El pasaje de la anunciación ha sido objeto de numerosos estudios; entre los más recientes destacan el de Prete (1992, pp. 55-80); el de Dupont (1995, pp. 327-332); el de Manicardi (1996, pp. 297-331); el de Stock (1999, pp. 61-73), y el de Mori (1988b, pp. 143-153). 
Virgen de Nazaret como madre del Hijo de Dios y, en consecuencia, es una elección del todo excepcional y única: por eso ella. Por todos estos motivos, la Madre del Redentor se convierte en el sacramento de la elección de la criatura humana por parte de Dios: esta elección es más fuerte que toda la experiencia de mal y de pecado, de toda aquella 'enemistad' con la que ha sido marcada la historia del hombre. En esta historia, María sigue siendo una señal de esperanza segura.

Al poner a la Virgen en el horizonte del Padre, la perspectiva teológica se dilata hacia la comprensión del proyecto original de Dios en el que el hombre fue llamado desde el comienzo a la comunión divina. Por otra parte, esta visión favorece la comprensión positiva del hombre creado en la gracia y elegido desde siempre en Cristo.

El punto de partida de la antropología teológica ha de ser el amor del Padre; por eso, antes de hablar del pecado de origen se ha de hablar de la gracia original en la que el hombre fue creado y amado desde el comienzo (Ladaria, 1983, pp. 173-194). La Theotokos se levanta como el paradigma de la imagen de Dios, la obra maestra de la Trinidad con vistas a la encarnación del Verbo. Podemos poner el saludo del ángel en relación también con las palabras de Isabel “¡Feliz la que ha creído que se cumplirían las cosas que le fueron dichas de parte del Señor!" (Lc 1, 45). Estos textos bíblicos (Ef, Ga, Lc) revelan la verdad sobre María, que procede de Dios Padre, en cuanto él la eligió como madre de su Hijo, y de la respuesta fiel que ella dio al inefable don del Padre. Aparece de nuevo la doble dimensión de la redención, de la cual la Madre de Cristo es la primera beneficiaria: por una parte, la acción de Dios Padre, que en Jesucristo, y por medio del Espíritu, se acerca al hombre para hacerlo partícipe de la comunión trinitaria, y, por otra, la plenitud que encuentra la criatura humana en esta comunicación divina. En Cristo estas dos dimensiones llegan a su plenitud, en cuanto él es uno de la Trinidad que se hizo uno de nosotros gracias a la respuesta total y fiel de María. En la revelación del Padre de Jesucristo por el Espíritu Santo aparece tanto la verdad sobre el misterio de Dios, uno y trino como la verdad sobre el ser humano llamado desde siempre a la comunión trinitaria.

En esta doble dimensión ocupa un lugar único la Madre del Redentor, la elegida del Padre para una misión excepcional en el proyecto salvífico. De hecho, en la anunciación aparece toda la Trinidad empeñada en la salvación del hombre $\mathrm{y}$, del mismo modo, la Virgen aparece como la primera persona que entabló un diálogo de fidelidad en la plenitud de los tiempos; en el sí de María resplandece la gratuidad de Dios y la dignidad de la criatura humana llamada a colaborar en el proyecto eterno de Dios (Forte, 1993, p. 174). A este respecto se tiene que: "el 
Padre de las misericordias quiso que el consentimiento de la que estaba predestinada a ser la Madre precediera a la encarnación para que, así como una mujer contribuyó a la muerte, así también otra mujer contribuyera a la vida"9 . De esta manera, el momento de la anunciación se convierte en la revelación del Dios Padre, rico en misericordia, que envía su ángel a María para colmar la esperanza de su pueblo y, más aún, de toda la humanidad. En la Virgen Madre, el Padre ofreció a toda la humanidad la prueba más densa de su misericordia.

Los textos bíblicos que hemos presentado nos dejan ver la predilección del Padre hacia la Virgen y han puesto en evidencia que la elección de María se fundamenta en la gratuidad del amor sobreabundante del Padre, que le ha donado la plenitud de su gracia y de su amor con vistas a la maternidad mesiánica. Las palabras del ángel ("Alégrate, llena de gracia, el Señor está contigo") revelan que el Padre ha estado desde siempre con ella, pues la plenitud de gracia anunciada por el ángel, significa el don de Dios mismo, es decir la elección de María como Madre del Hijo de Dios. En el acontecimiento de la anunciación se pone de manifiesto el donarse salvífico de Dios a la humanidad; se revela también la plenitud de la santidad de la Madre de Jesús; su virginidad es signo de su total abandono a la voluntad del Padre y del descubrimiento del don; es signo de pobreza y de total abandono a la providencia del Padre.

La grandeza de la Virgen María y, más aún, del hombre se funda en el encuentro entre el favor divino del Padre y la plena disponibilidad humana. Es en la elección del Padre en donde se manifiesta la condición filial que el hombre ha recibido por medio de Jesucristo (Ef 1, 4-6). Por tanto se puede afirmar que la vocación de todo cristiano se realiza en la filiación ${ }^{10}$; María fue la primera que vivió esta experiencia filial mediante la elección por parte del Padre para una comunión inefable con su Hijo divino. Ella vivió la experiencia de la paternidad divina como maternidad filial; no deja de ser hija por ser madre, y realiza de un modo especial la filiación en comunión con su Hijo por la acción del Espíritu. Así

\section{CEC 488.}

10 Confrontar Ladaria (1983, pp. 367-376). Ladaria advierte además: “La filiación de Jesús es el modelo a partir del cual también nosotros podemos ser considerados hijos. Su filiación es por tanto el fundamento de la nuestra. Jesús, el Hijo, posibilita con su encarnación que nosotros podamos ser también hijos de adopción [...]. La vida del hijo de Dios consiste en participar en la relación que Jesús tiene con el Padre; en efecto, en virtud de nuestra unión con Cristo, de la filiación que la encarnación posibilita (cf. Ga 2, 20), podemos dirigirnos a Dios con la palabra abba. Esto es posible porque nos mueve el Espíritu del Hijo que Dios ha enviado" (pp. 371-372). Además revisar Ruiz de la Peña (1992, pp. 379-384). 
como el Hijo fue todo del Padre y todo dirigido hacia el Padre, también ella fue toda del Padre y toda dirigida hacia el Padre.

Por tanto el amor filial de los cristianos hacia la Madre del Señor ha de conducir - si es auténtico - a un amor filial más ardiente hacia el Padre, a descubrir la confianza que Dios Padre tiene en el ser humano, ya que él tuvo confianza en una mujer para la encarnación de su Hijo. Todos estos aspectos de la paternidad divina adquieren pleno significado en la situación actual de la humanidad que necesita volver a confiar en el Padre para así confiar en el hermano, viviendo en el amor que procede de Dios Padre. La experiencia de la paternidad de Dios hace que la persona humana descubra su verdadera dignidad y su identidad de criatura re-creada por medio de Cristo. En este sentido, la Madre del Redentor constituye para toda la humanidad el paradigma de la criatura re-creada por el Dios Padre en Jesucristo Nuestro Señor.

\section{La respuesta total y libre de María al Padre}

En este apartado, se pretende indicar cómo la Virgen de Nazaret respondió al don del Padre; fundamentalmente, se desarrollará el tema de la fe de María como respuesta generosa e inmediata a la elección amorosa del Padre. Los pasajes bíblicos que considero para presentar este tema son el de la anunciación y el de la visitación. Podemos partir en nuestra reflexión, de la constitución dogmática del Concilio Vaticano II Dei Verbum sobre la revelación: "'Cuando Dios revela hay que prestarle la obediencia de la $f e^{\prime}[. .$.$] , por la que el hombre se confía libre y$ totalmente a Dios"11. Esta descripción de la fe encontró una realización perfecta en María, en la medida en que ella respondió al don del Padre con la generosidad más radical, expresando su consentimiento a su proyecto salvífico.

- En la anunciación, la Virgen respondió a la llamada de Dios con una disponibilidad plena: "He aquí la esclava del Señor" (Lc 1, 38)12. La respuesta de María fue una respuesta de fe y de obediencia. La expresión

11 Dei Verbum 5.

12 TMA 54. San Francisco de Asís en una de sus oraciones invoca a María como hija y sierva del Padre: "figlia ed ancella dell'altissimo Re e Padre celeste" (citada en van Asseldonk, 1982, p. 1128); el Vaticano II llamó a María "Hija predilecta del Padre" (LG 53). Un estudio completo sobre el título "esclava del Señor" se encuentra en Mori (1988c, pp. 253-309). 
esclava del Señor ${ }^{13}$ adquiere un significado de obediencia confiada al Padre y aceptación de su voluntad mediante la participación en la encarnación del Hijo; en esta expresión salida de su fe, se deja traslucir toda la conciencia que María tiene de ser criatura en relación con Dios. Aquello que Israel no logró llevar a plenitud por su incredulidad y desobediencia, lo llevó a cabo la Virgen de Nazaret por su obediencia al Padre. Así como Israel comenzó con el acto de fe de Abraham así el Nuevo Israel comienza con la obediencia de la fe de María (Amato, 2001, p. 607). El camino que el Padre trazó para su Hijo, lo trazó también para la Madre. Como el Hijo, también ella se abandona con la máxima libertad a la voluntad del Padre.

El fiat que María pronunció en la anunciación es sobre todo fruto de la donación total a Dios en la virginidad (Colzani, 1996, p. 177); es abandono a la voluntad del Padre y confianza absoluta en él; su virginidad se convierte así en el signo de que ella fue desde el primer instante de su existencia toda de Dios Padre. Ella desde el principio entendió la elección por parte del Padre a la maternidad como donación total de sí, de su persona, al servicio de los designios salvíficos del Altísimo. Por otra parte, "la llamada de Dios no anuló su ser persona, su creatividad en la respuesta, su dimensión plenamente humana y femenina: ella ha respondido, por tanto, con todo su yo humano, femenino", lo que corrobora así que la gracia no anula la persona, sino que al contrario la abre a dinamismos únicos de respuesta humana como signo de que toda la acción de Dios en la historia de los hombres respeta siempre la voluntad libre del yo humano.

- En la visitación, vemos la confirmación de la respuesta de la Virgen a la elección del Padre: justamente, por ello, Isabel alaba a María - “¡Feliz la que ha creído que se cumplirían las cosas que le fueron dichas por parte del Señor!" (Lc 1, 45) - ; esto quiere decir que el don del Padre se convierte en un motivo de alabanza y en una definición de la persona de María, pues estas palabras de Isabel no se aplican únicamente a aquel momento concreto de la anunciación, sino a toda la existencia

13 "El título 'esclava del Señor' -lo mismo que ebed Yahveh del A. T.- significa obediencia al Padre y aceptación de su plan de redención por medio de la encarnación del Hijo" (Amato, 2001, p. 607; Calero, "Esclava del Señor y esclavitud mariana", 625-638). 
de la Madre de Cristo. La anunciación representa para ella un punto de llegada (la fe de María a la espera de Cristo) y un punto de partida (inicio de su camino de fe hacia el Padre) ${ }^{14}$. De esta manera se pone la fe de María en el contexto de la espera mesiánica de Israel; en ella culmina la fe del Antiguo Testamento y en ella comienza la fe del Nuevo Testamento en cuanto camino en Cristo hacia el Padre. Esta fe, por tanto, tiene analogías con la fe de Abraham, que creyó en las palabras de la promesa de la primera alianza; sin embargo ella supera a Abraham. El fiat y el Magnificat fueron la respuesta a la misericordia del Padre que se derramó abundantemente sobre ella: el ángel la había invitado a alegrarse, ahora María expresa el júbilo de su espíritu en Dios su salvador.

\section{El culto mariano como camino fecundo hacia el Padre}

El culto mariano favorece a quien lo practica según el espíritu de la Iglesia, la adoración al Padre y al Espíritu Santo. Efectivamente, al reconocer el valor de la maternidad de María, los creyentes descubren en ella una manifestación especial de la ternura de Dios Padre, de un Dios que comparte las alegrías y sufrimientos de la humanidad; así el creyente se orienta hacia el Dios Salvador proclamado en el Magnificat, a sabiendas de que existe una distancia infinita entre el culto mariano y el que se le rinde a la Santísima Trinidad. La Madre del Señor se presenta en la liturgia como un modelo de itinerario al Padre por Cristo en el Espíritu. En la celebración litúrgica se realiza un doble movimiento: "todo nos viene del Padre, por medio de su Hijo encarnado, Jesucristo, en la presencia en nosotros del Espíritu Santo; de este modo, en la presencia del Espíritu Santo, por medio del Hijo encarnado, Jesucristo, todo debe retornar al Padre y alcanzar su fin último,

14 El Catecismo interpreta la oración de la Virgen de Nazaret en el radio de la historia salvífica: "la oración de María se nos revela en la aurora de la plenitud de los tiempos. Antes de la encarnación del Hijo de Dios y antes de la efusión del Espíritu Santo, su oración coopera de manera única con el designio del Padre: en la anunciación, para la concepción de Cristo; en Pentecostés, para la formación de la Iglesia, cuerpo de Cristo. En la fe de su humilde esclava, el don de Dios encuentra la acogida que esperaba desde el comienzo de los tiempos. La que el Omnipotente ha hecho 'llena de gracia' responde con la ofrenda de todo su ser: 'He aquí la esclava del Señor, hágase en mí según tu palabra'. Fiat, esta es la oración cristiana: ser todo de él, ya que él es todo nuestro" (CEC 2617). 
la Trinidad beatísima"15. La Virgen Madre ocupa un lugar particular en la liturgia cristiana por su presencia única y excepcional en el proyecto salvífico del Padre; por ser la Madre del Hijo encarnado y por su relación particular con el Espíritu Santo, ella se convierte, así, en modelo para la Iglesia del culto que esta ofrece al Padre ${ }^{16}$; el culto a la Theotokos debe conducir a la adoración y al amor hacia el Padre. El Magnificat es memoria del actuar salvífico de Dios en la historia y a la vez adoración al Padre por las obras que ha realizado y particularmente por su misericordia eterna. La hija predilecta se ofrece como modelo de fe, de oración, de silencio fecundo en la adoración del misterio.

\section{Conclusión}

El planteamiento histórico salvífico nos permite ver las implicaciones de la relación de María con el Padre: su situación de criatura, su elección eterna, su perfecta filiación en el Espíritu, su vocación de Madre del Salvador; su colaboración materna en el misterio de la encarnación; su disposición a colaborar en la realización de su proyecto salvífico y su entrega, total a la causa de su Hijo. Por tanto, al final de este estudio se puede responder a dos interrogantes que han venido acompañando la exposición del tema: en primer lugar, ¿cómo se manifiesta el Padre, que ha elegido a María como Madre de su Hijo? Se puede responder que el Padre se manifiesta en María como el que se entrega con extrema gratuidad, como la fuente y el principio de toda la divinidad, como aquel que desde siempre y gratuitamente comenzó a amar, como un Padre empeñado en la salvación de la humanidad. En segundo lugar, ¿qué imagen de criatura humana aparece en la figura de la Madre de Dios, ícono de la paternidad divina? En ella se puede contemplar a la criatura humana tal como Dios la quiso desde el principio y tal

15 Confrontar Vagaggini (1965, p. 184), y CEC 1077-1083.

16 Cuando la Iglesia hace memoria litúrgica del misterio de María se encuentra con el actuar de Dios en la historia, ya que, María remite al misterio de Dios y al mismo tiempo lo refleja en sí misma de una manera única. Véase Pablo VI (1976, pp. 25-28) sobre las notas trinitaria, cristológica y eclesial del culto mariano; (1976, pp. 29-37) sobre las orientaciones bíblica, litúrgica, ecuménica y antropológica del culto a María, y (1976, pp. 56-58) sobre el valor teológico y pastoral del culto a la Madre de Dios. Forte afirma: "El culto a la Virgen Madre no sustituye por tanto en lo más mínimo el culto que se debe a la Trinidad santa, sino que encuentra por el contrario en la economía trinitaria de la salvación - en la que María es elegida y envuelta por la gracia - su fundamento más sólido y lleva a glorificar en la Madre de Dios las obras maravillosas del Padre, del Hijo y del Espíritu Santo" (1993, p. 234). 
como Dios la llama a participar de la comunión trinitaria, invitada a existir en la gratuidad, a responder con plena libertad a la elección divina.

La Madre de Dios da testimonio de que la vocación suprema del hombre es a la comunión con el Padre por medio de Cristo en la fuerza del Espíritu Santo; igualmente informa acerca de que la criatura humana está llamada a irradiar en su existencia el amor del Padre, a vivir en la libertad de los hijos y en el abandono al Padre. La Madre de Dios es, para nosotros, el modelo perfecto de la vida filial, pues ella fue la primera criatura humana llamada a ser hija predilecta del Padre, a quien el Padre pensó y a quien eligió para que fuera la Madre del Salvador; y de esta manera, la que fue objeto de la predilección del Padre; ella anticipa en su vida el camino de todos los redimidos y se constituye por su abandono filial a la voluntad del Padre, en nuestra Madre en la fe y en signo de segura esperanza para todos nosotros. La singular comunión de vida y de amor que se establece con el Padre en virtud de la maternidad divina hace de María "el gran signo del rostro maternal y misericordioso, de la cercanía del Padre"17. Por todo lo anterior la experiencia filial de la Madre de Cristo se convierte para el cristiano en paradigma de espiritualidad cristiana: vivir como hijos en el Padre.

17 Confrontar CELAM (1979, p. 282) y Forte (1993, p. 225). 


\section{Referencias}

Aldama, J. (1995). María en sus relaciones con la Santísima Trinidad. Mariología fundamental: María en el Misterio de Dios (pp. 305-316). Salamanca: Secretariado Trinitario.

Amato, A. (2001). Dios Padre. En Nuevo diccionario de mariología. Madrid: San Pablo.

Amato, A. (2000). María y la trinidad: Espiritualidad mariana y existencia cristiana. Salamanca: Secretariado Trinitario.

Amato, A. (1998). El evangelio del Padre (Vol. 38). Salamanca: Secretariado Trinitario.

Bertetto, D. (1988). Maria la serva del Signore: Trattato di mariologia (1.st ed.). Napoli: Edizioni dehoniane.

CELAM. (1979). Conferencia General del Episcopado Latinoamericano.

Concilio Vaticano II. (1964). [LG] Constitución Dogmática sobre la Iglesia Lumen Gentium.

Concilio Vaticano II. (1965). [DV] Constitucion dogmatica sobre la divina revelacion Dei verbum.

Colzani, G. (1996). Maria, mistero di grazia e di fede. Madrid: San Pablo.

De Fiores, S. (1990). María en la teología contemporánea. Sígueme: Salamanca.

De la Poterrie, I. (1988). La “Figlia di Sion" nel mistero dell'alleanza. La Civiltà Cattolica, $1,535-549$.

Dupont, J. (1995). L'Annuncio a Maria. Theotokos, 3(2), 327-332.

Forte, B. (1993). María la mujer icono del misterio. Ensayo de mariología simbólico-narrativa. Salamanca: Sígueme.

Iglesia Católica. (1992). [CEC] Catecismo de la Iglesia católica. Madrid: Asociación de Editores del Catecismo.

Ladaria, L. F. (1983). Antropología teológica. Madrid: Universidad Pontificia Comillas.

Laurentin, R. (1954). L'interprétation de Gen 3,15 dans la Tradition. Études mariales, 12.

Manicardi, E. (1996). L'annuncio a Maria. Lc 1,26-38. Theotokos, 4(2).

Mori, E.G. (1988). Hija de Sión. En Nuevo diccionario de mariología. Madrid: San Pablo.

Mori, E.G. (1988b). Anunciación del Señor. En Nuevo diccionario de mariología. Madrid: San Pablo.

Mori, E. G. (1988c). Figlia di Sion e serva del Signore: nella Bibbia, nel Vaticano II, nel postconcilio. Bologna: Edizioni Dehoniane.

Navarro, M. (1987). Claves teológicas de la Mariología actual. Sal Terrae, 89.

Pablo VI. (1976). Exhortación apostólica Marialis cultus. 
Pastor, F. A. (1999). 'Credo in Deum Patrem': Sul primo articolo della fede. Gregorianum, 469-488.

Pikaza, X. (1994). Hija de Sión, origen y desarrollo del símbolo. Ephemerides Mariologicae, XLIV.

Juan Pablo II. (1994). [TMA]. Carta apostólica Tertio millennio adveniente.

Prete, B. (1992). Il genere letterario di Lc 1, 26-38. Ricerche storico-bibliche, 4.

Ruiz de La Peña, J. L. (1991). El don de Dios. Santander: Sal Terrae.

Sartori, L. (1999). Dio Padre e Maria. Theotokos, 758.

Stock, K. (1999). María, la Madre del Señor en el Nuevo Testamento. Madrid: Edibesa.

Vagaggini, C. (1965). El sentido teológico de la liturgia. Madrid: BAC.

Van Asseldonk, O. (1982). María, sposa dello Spirito Santo in S. Francesco d'Assisi. Laurentianum, 23, 414-423. 